\title{
Schedule and Cost Control in Dwelling Construction Using Control Charts
}

\author{
Madelyn Marrero ${ }^{1, *}$, Antonio Fonseca ${ }^{2}$, Raúl Falcon $^{3}$ and Antonio Ramirez-de-Arellano ${ }^{1}$ \\ ${ }^{1}$ University of Seville, Department of Building Construction II, Ave. Reina Mercedes 4A, Seville, Seville 41012, Spain; \\ ${ }^{2}$ Self-employed Technical Architect; ${ }^{3}$ University of Seville, Department of Applied Mathematics I, Ave. Reina Mercedes \\ 4A, Seville, Seville 41012, Spain
}

\begin{abstract}
Methods to monitor the schedule and to control cost in dwelling construction projects are numerous and varied but commonly constitute an obstacle to a fast and agile response by construction managers, whose decisions require information to be comprehensive and summarized. A simple model to monitor these projects is proposed that can easily be implemented within control systems that are already in place. For the first time, process control charts are combined with cost control in dwelling construction in order to prevent overruns in terms of time and/or cost. The model facilitates the production supervision of construction contracts by regularly providing information on the work completed and the incurred cost of the production processes per period, through charting and/or summarizing this information in a manner consistent with statistical control charts. Finally, the manager can easily identify those processes which are off target by consulting control charts.
\end{abstract}

Keywords: Cost control, dwelling construction, project management, scheduling, statistical process control, work breakdown system.

\section{INTRODUCTION}

Over the last decade, an abundance of project control methods have been developed and a variety of software packages have become available to support their application, [1-3]. However, project planning and cost control still remain an open issue. Olawele and Sun [4] performed a survey to establish the current common practice of time and cost control in the UK construction industry, and include control methods and software applications in use. They identified the importance of cost and time control; already widely recognized by construction professionals. Their questionnaire survey reveals that $58 \%$ of respondents always apply time controls to their project and an overwhelming $84 \%$ implement cost control methods. These authors also identify the most popular time-planning and control techniques. The Gantt Bar Chart [5] is the most widely used, closely followed by the Critical Path Method [6]. Another commonly used technique is the Program Evaluation Review Technique, PERT [6]. The use of software support is widespread. Olewale and Sun [4] also detected that the cost control techniques most commonly used in practice, in about $70 \%$ of surveys, are project cost-value reconciliation, overall profit and loss, profit and loss at valuation dates, and reconciliation of actual versus forecast labour/plant/material.

Despite the wide variety of control techniques and software available, construction projects are still subject to cost and time overruns. Researchers have been adapting previous techniques to more precise prediction levels through the

*Address correspondence to this author at the University of Seville, Department of Building Construction II, Ave. Reina Mercedes 4A, Seville, Seville 41012, Spain; Tel: (34) 954-55-6667;

Email: madelyn@us.es implementation of stochastic instead of deterministic models. For example, approximations are used in the estimation of the mean and variance of the completion time for a PERT network and the task durations are approximated by employing normal distributions [7]. Other work related to stochastic models focuses on the planning and execution of construction projects, and account for the variability inherent in the duration and cost of the scheduled activities by simultaneously applying range estimation and probabilistic scheduling to historical data [1]. More recently, stochastic analysis by a multiple simulation analysis technique using Monte Carlo simulation has been used to evaluate the impact of noncritical activities for which the deterministic critical path method is insufficient [2].

In industrial processes, certain factors of stochastic behaviour exist whose influence on the process determines variations in the quality of the final product. In order to predict and control this influence, several methods have been developed, such as Statistical Process Control (SPC) [8] which uses statistical indicators to identify common causes of quality variation in manufacturing processes and to reduce the cost. An introductory survey on the subject appears in [9]. Specifically, the result of applying a repetitive process can be represented by a normal distribution whose mean and standard deviation are related to a single quality parameter. Multivariate analyses based on SPC, which are more common in practice, have also been developed over the last two decades [10-12]. In both uni- and multi-variate analysis, statistical measures, such as mean and standard deviation, determine the tolerance levels of the variation with respect to the target, which can be represented in a control chart with regard to time. These charts clearly and promptly show abrupt fluctuations and indicate whether they are due to ei- 
ther a random or an unknown factor which should consequently be taken into account [13]. Thus, managers can adopt corrective decisions in order to reach the final target. More specifically, in the construction industry, SPC has successfully controlled road construction [14] and, combined with the Earned Value Management (EVM) method, project cost and schedule performance have been controlled [15].

In the current paper, a new model to monitor the schedule and to control cost is proposed which adapts, for the first time, SPC control charts to dwelling construction. Dwelling construction usually consists of simple projects for which repetitive work takes place, which makes it possible for the tools already being used in the control of the manufacturing process to be adapted to control the construction process.

Once the schedule is established, by either a deterministic or stochastic approach, it can be controlled and deviations can be corrected. In the present model, schedule and cost control in projects are handled simultaneously. Many models handle resources separately and independently from the time factor, and the cost model is disconnected from the time model, thereby rendering cost and time control difficult and imprecise. Researchers have identified the benefits from integrating cost and schedule control. This is the case of management control by means of the Earned Value Management System (EVMS) which determines the actual costs accumulated and compares them to the earned value [16]. This value is used as a baseline to which the planned schedule (budgeted cost for work scheduled), and the actual cost (actual cost of work performed), are compared in order to measure the schedule performance and cost performance, respectively. The results of performance variances and indices are used for further analysis, which include identifying latent risks, and re-scheduling the remaining work [3].

Following the EVMS approach, the main objectives include the development of a simple tool that allows project managers rapid and agile responses to out-of-budget and/or out-of-schedule processes on the construction site. Three key characteristics are taken into account: a simple structure, ease in data collection, and ease in following the process.

\section{METHODOLOGY}

The main divisions of the model are similar to those used in EVMS: data input, work scheduling, data transformation into reference values, and comparison between the work actually carried out and planned work completion.

The steps are the following:

- Enter the data of the initial schedule.

- Plan work in terms of cost, using the project schedule.

- Plan work quantities.

- Distribute expected costs and quantities over time periods.

- Enter actual values of work performed and cost produced.

- Compare actual data values against planned data values.

- Calculate cost deviations, and quantity deviations.

- Generate reports for each time period.
- Edit, revise or modify the schedule according to new forecasts.

- Once the schedule is corrected, recalculate the new planned work.

The first step, Enter the data of the initial schedule, refers to the original project budget and its planning, (see Fig. 1). The classification of the costs is obtained from this budget which is organized by means of a work breakdown structure (WBS). The schedule is obtained from the first plan of the project, which allows the work to be distributed into steps for each time period: Plan cost and Plan work quantities in (Fig. 1) constitute the "Schedule". This distribution is then used to calculate the accumulative cost and quantities for each period in the step Distribute expected cost and quantities, and is represented in (Fig. 1) as the "Images".

Another set of data is obtained by means of surveys at the construction site, and contains information on the quantities of work performed and costs incurred. This data is compared with the planned values, by subtracting the planned values from the actual values, thereby indicating that an overrun is taking place if a positive value is obtained. The differences during each period are transformed into indicators in the "Evaluation" step in (Fig. 1), and are represented in a control chart. Finally, a report is written. The schedule is readjusted accordingly and a new work distribution is generated for future comparisons. In the following sections, we define and study each step of (Fig. 1) in more detail.

\subsection{The Data}

As established in the previous section, the data needed is the original project budget and planning. The costs are obtained from this budget and the schedule from the initial project time chart. One major aspect in process control is data measurement and accuracy. The method, structure, data, and accuracy of detailed measurement may vary depending on the specific characteristics of a project. This situation can lead to misinterpretation of the project status, especially under a multi-project management environment. In order to overcome this issue, Jung and Kang [3] propose a standard progress measurement package which addresses issues for the standardization of the work breakdown structure (WBS). These authors have identified the measurement of the level of progress as a critical factor in terms of the workload required to maintain both the control system and the accuracy. In order to address this issue, the level of detail for progress measurement should be carefully selected as a trade-off between the workload and accuracy, by incorporating strategy, objectives, and management policy of construction projects.

All WBSs have the same goals and similar methodologies. The basic concept in all of these systems is to divide a complex problem into simpler parts that can then be aggregated to define the development of a complete construction. Many researchers have been working on the development of construction information classification systems (CICS): Kang et al. [17] for civil work; Eldin [18]; and Jung et al. [3] who address cost and scheduling simultaneously. There are several international CICS, of which the most frequently used include: Masterformat [19], Uniformat II [20], the Civil Engineering Standard Method of Measurement [21], CI/SfB [22], Uniclass [23], and Omniclass [24]. 


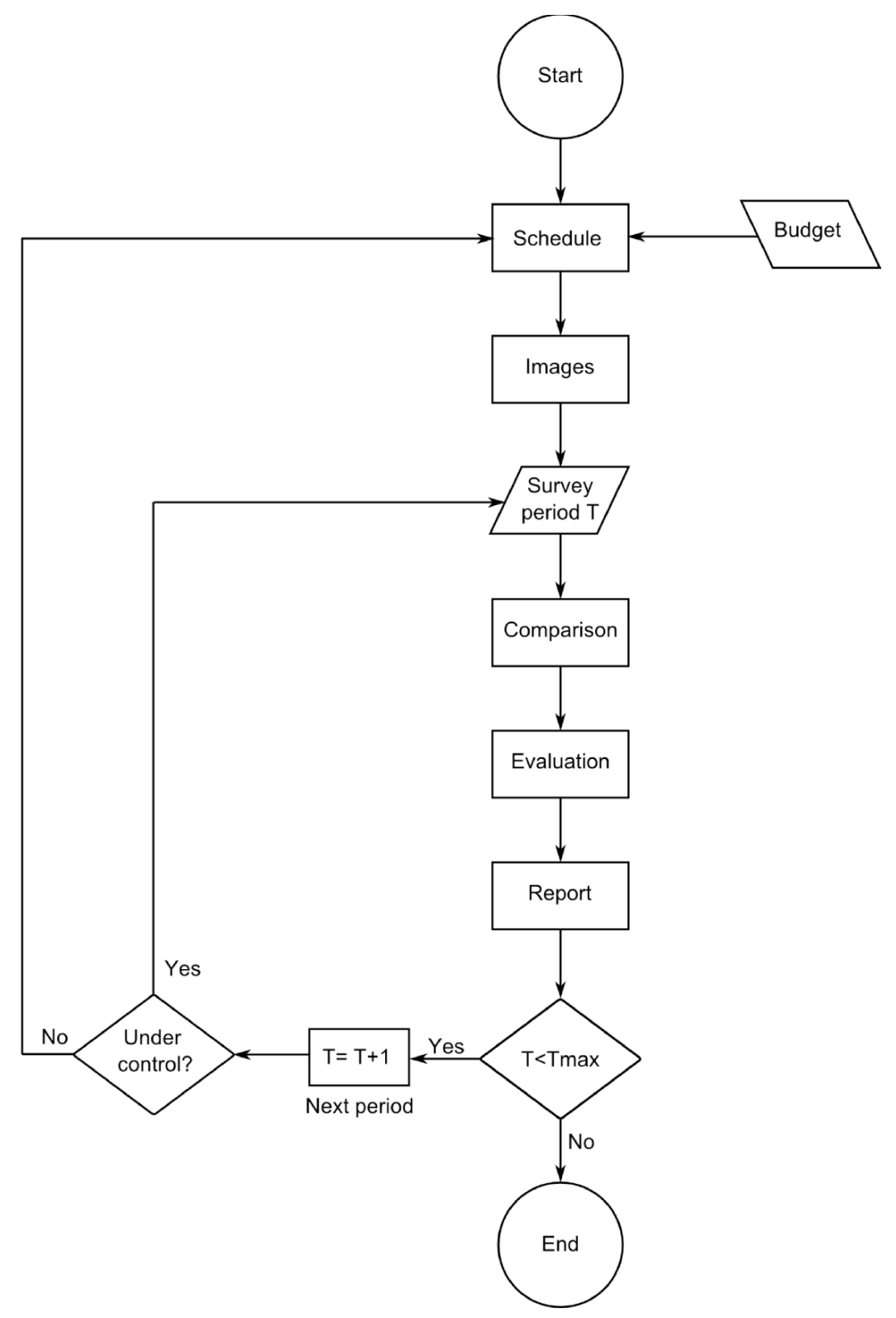

Fig. (1). Steps of the control process.

In particular, the present model uses the Andalusia Construction Information Classification System (ACICS) [25]. Its most extended usage is for estimating cost in dwelling construction and it is mandatory in all public developments in Andalusia, Spain. This system divides work units into a hierarchical organization. The highest level is the construction site, L1 in Table 1. The next divisions are called chapters, L2 in Table 1, and each represents a construction process: Demolition, Earthwork, Foundations, Water disposal, Structures, Partitions, Roof, Installations, Insulations, Finishes, Carpentry, Glass and Polyester, Coating, Decoration, Urbanization, Safety, and Waste Management.

The subsequent divisions are the sub-chapters. For example, the chapter called "Installations" is divided into the following sub-chapters: Air conditioning, Electricity, Water, Communications, Gas, Electro-mechanic appliances, Fire protection, and Illumination [26].
Since time and cost are closely related, it can be assumed that a close relationship exists between the cost estimate and schedule. However, it is not easy to numerically evaluate the extent to which these parameters affect each other, due to differences in their breakdown structures [27]. Even though ACICS is developed for the generation of construction budgets, it can also be used for the definition of the schedule. In order to double-check the work development, a second classification system is proposed to control quantities instead of cost. The classification, complex groups, is employed to control construction and demolition waste successfully [28, 29]. The complex groups are at the same level as sub-chapters in the ACICS hierarchy. The existence of complex groups allows the combination of similar work units within a chapter, which would not be possible if ACICS sub-chapters were used. For example, earthwork excavations, such as the foundation (02AVV00002), trenches (02ZMM00002), and pits (02PMM00002), have different unitary costs and belong to 
separate sub-chapter classifications in ACICS: 02A, 02Z, and $\mathrm{O} 2 \mathrm{P}$, respectively, but can still be grouped together into a "complex group", 02EX, since the main activity is common to all of these work units and they can take place during the same period of time, thereby rendering it possible for them to be controlled simultaneously.

Table 1. Internal classification structure.

\begin{tabular}{|c|c|}
\hline Class Level & Definitions \\
\hline L1. Construction site & $\begin{array}{l}\text { All the constructive elements that make up a } \\
\text { construction site. }\end{array}$ \\
\hline L2. Chapter & $\begin{array}{l}\text { Element sets with a common characteristic. } \\
\qquad \text { e.g.: 05. Structures. }\end{array}$ \\
\hline L3. Sub-chapter & $\begin{array}{l}\text { Chapter division into smaller sets with a com- } \\
\text { mon characteristic. } \\
\text { e.g.: } 05 H \text {. Concrete. }\end{array}$ \\
\hline L4. Section & $\begin{array}{l}\text { Sub-Chapter division into smaller sets with a } \\
\text { common characteristic. } \\
\text { e.g.: } 05 H H \text {. Reinforced concrete. }\end{array}$ \\
\hline L5. Group & $\begin{array}{l}\text { Section division into smaller sets with a common } \\
\text { characteristic. } \\
\text { e.g.: 05HHJ. Reinforced concrete beam. }\end{array}$ \\
\hline L6. Work unit & $\begin{array}{l}\text { Group division into unitary elements. } \\
\text { e.g.: } 05 H H J 00001 \mathrm{~m} 3 \text { Concrete HA-25 in.... }\end{array}$ \\
\hline
\end{tabular}

The budget is introduced into two different scenarios, work quantities and cost, which is possible since the budget is the result of the addition of all work units that constitute the project, multiplied by their corresponding unitary price. For the first scenario, the sub-chapter cost is defined as,

$$
C_{s}^{T}=\sum_{i=1}^{l} Q_{i} P_{i}
$$

where $C_{s}^{T}$ is the total cost of sub-chapter "s", and $Q_{i}$ and $P_{i}$ are the quantity and price of the work unit " $i$ ", which is part of the level "l" total in sub-chapter "s".

The second scenario is for the complex quantities, which are formed of similar work units within the same chapter of the ACICS,

$$
Q_{g}^{T}=\sum_{i=1}^{m} Q_{i}
$$

where $Q_{g}^{T}$ is the total quantity of complex group " $\mathrm{g}$ ", and " $m$ " is the total number of divisions that are part of the complex group, which implies that all work units in a complex group have the same units of measurement, (cubic metres of concrete, tons of steel, etc).

In order to be able to add and compare widely varying quantities, a coefficient is defined which transforms all quantities into a similar magnitude, $\mathrm{D}_{\mathrm{g}}$,

$$
D_{g}=\frac{P_{g}}{P_{\max }}
$$

where $\mathrm{P}_{\mathrm{g}}$ is the average unitary price of the complex group " $g$ " which is measured in monetary units, divided by the corresponding measurement unit, and where $\mathrm{P}_{\max }$ is the unitary price of the most expensive work unit in the project, divided by the corresponding measurement unit. For dwelling construction, the most expensive unitary price, $\mathrm{P}_{\max }$, is normally the average price of all bathroom appliances. This approximation establishes the quantity importance in terms of its proportional unitary price with respect to the most expensive item in the project. The measurement units of $D_{g}$ are therefore

$$
D_{g}=\left(\frac{u_{\text {max }}}{u_{g}}\right)
$$

where $u_{\max }$ is the unit of the most expensive item, and $u_{g}$ is the group "g" measurement unit. Finally, all complex groups lie within the same complex measurement unit,

$$
Q_{g} \times D_{g}=u_{g} \times\left(\frac{u_{\max }}{u_{g}}\right)=u_{\max }
$$

Several ASICS work units, which require similar materials, labour, and machinery, are grouped together and their cost is defined as an average. This average cost is subsequently divided by the most expensive work unit in the project, thereby obtaining $\mathrm{D}_{\mathrm{g}}$. For example, in a project where bathtubs are the most expensive work unit at 200 Euro/unit, then $30 \mathrm{~m}^{3}$ of refilling soil (at 5 Euro/ $\mathrm{m}^{3}$ ) is transformed into $0.01 * 30=3$ units. On the other hand, $30 \mathrm{~m}^{3}$ of reinforced concrete trenches (at $200 \mathrm{Euro} / \mathrm{m}^{3}$ ) is transformed into 30 units. Finally, the $D_{g}$ factor is able to establish that $30 \mathrm{~m}^{3}$ of concrete is more important than $30 \mathrm{~m}^{3}$ of refilling soil due to its unit costs. The advantage of the alternative approach is that different cost estimation is obtained of the cost of the work performed on the construction site, rather than just the cost that is certified and ready for payment. The new quantity approach is independent of market conditions and cost fluctuations since the unitary costs are transformed into a proportion of the original market price, at the beginning of the project, with respect to the most expensive unitary price: the $\mathrm{D}_{\mathrm{g}}$ factor. The quantity approach is easily implemented due to the hierarchical nature of the ASICS structure: the families of similar work belong to the same chapter and sometimes to the same sub-chapter. This is the case of reinforced concrete slab (03HAL10002) and reinforced concrete wall (03HAW10007), which belong to sub-chapter $03 \mathrm{H}$ and to "complex quantity" 03HA.

\subsection{The Schedule}

Once the project budget of cost and quantities has been separately input following the ACICS hierarchy, the next step is to define the schedule, also in terms of ACICS. The schedule, which is additional data, is input in two scenarios, one for the cost and another for its corresponding quantities, in terms of ACICS and the complex quantity classification system, respectively. The work quantities and cost are then distributed over the duration of the construction, thereby creating reference scenarios for the actual labour/plant/material versus those planned. 
The work units are distributed in time periods, $T_{k}$, where the time distribution can be either in terms of manpower hours, days, weeks, machine hours or of any other characteristic that is proportional to the time necessary to perform the work [27], or in terms of program measurement packages [3]. The work amount in period " $k$ " is called weight, $\mathrm{W}_{\mathrm{sk}}$ and $\mathrm{W}_{\mathrm{gk}}$, where " $\mathrm{s}$ " or " $\mathrm{g}$ " is the subchapter or group of which the weight is a component, respectively.

The entire project is planned at the beginning of the controlling process and the planning is revised when the actual work carried out deviates from the work planned.

\subsection{The Images}

Once the project budget and schedule have been input, then the next step is to create the reference image scenario. In this section the term image refers to the representation of the scheduled costs and complex quantities in time. There is an image, planned cost per time period, for each sub-chapter which becomes the reference value. Another image is generated for the complex quantities per period [27]. Thus, if "n" is the total number of periods of the project, then the cost reference images are defined by:

$$
C_{s k}^{P}=C_{s}^{T} \frac{W_{s k}}{\sum_{k=1}^{n} W_{s k}}
$$

where the planned cost $C_{s k}^{P}$ of sub-chapter "s" in period "k" is obtained as the product of the total cost $C_{s}^{T}$ of sub-chapter "s" obtained from the budget multiplied by the relative proportion of the work to be carried out during such period and sub-chapter, divided by the sum of all the proportions.

In a similar way, the second scenario is defined for the quantities, whereby the reference images are obtained from,

$$
Q_{g k}^{P}=Q_{g}^{T} \frac{W_{g k}}{\sum_{k=1}^{n} W_{g k}}
$$

where $Q_{g k}^{P}$ is the planned quantity of complex group "g" in period "k",$Q_{g}^{T}$ is the total amount of the complex group "g" obtained from the original budget, and $W_{g k}$ is the proportion of the work of complex group " $\mathrm{g}$ " to be carried out in period "k", and " $\mathrm{n}$ " is the total number of periods.

\subsection{Survey}

Once the quantity and cost scenarios are established, then the actual work carried out is noted in a survey during each construction period, which can be defined in terms of days, weeks, or months, depending on the level of time control. The cost survey consists of information about the completed work on the construction site for which the subcontractors are to be paid. The survey is organized in the WBS budget, which is familiar to the construction managers; this aspect facilitates its implementation. The information is normally checked on the construction site in order to control cost as established in the Spanish law on Public Sector Contracts [30].

\subsection{The Comparison}

Once the survey data is input, the differences between the images for planned quantities and cost and their actual values are determined. Positive differences show overruns and negative differences show work carried out under budget, and constitute the first control level for the construction site manager.

In the succeeding control level, deviation indicators are defined,

$$
\begin{aligned}
& V_{s k}=\frac{C_{s k}^{R}-C_{s k}^{P}}{\sum_{s=1}^{p} \sum_{k=1}^{n} C_{s k}^{R}} \times 100 \\
& V_{g k}=\frac{\left(Q_{g k}^{R}-Q_{g k}^{P}\right) \times D_{g}}{\sum_{g=1}^{q} \sum_{k=1}^{n} Q_{g k}^{P} \times D_{g}} \times 100
\end{aligned}
$$

where $V_{s k}$ is the cost deviation indicator of sub-chapter "s" during period " $k$ " for " $p$ " total sub-chapters and " $n$ " total periods. The indicator is the percentage of cost deviation with respect to the total project budget, and $C_{s k}^{R}$ and $C_{s k}^{P}$ are the actual and the planned costs, respectively.

In the second scenario, $V_{g k}$ is the quantity deviation indicator, $Q_{g k}^{R}$ and $Q_{g k}^{P}$ are the actual and the planned quantities, respectively, of group "g" during period "k" for "q" total groups and "n" total periods. The indicator $V_{g k}$ is the quantity deviation as a percentage with respect to the total project budget.

The total number of groups, g, and the total number of sub-chapters, $p$, that are part of a chapter, are not fixed since not all dwelling projects are made up of the same number of sub-chapters or groups.

The indicators $V_{s k}$ and $V_{g k}$ are positive values when the process is more expensive than planned or ahead of schedule, respectively, and negative otherwise. Only one indicator is reported per chapter, and is determined as an average value of all the sub-chapter indicators. This assumption allows a simple calculation of the total chapter indicator. For chapter "c" during period " $k$ ", the deviation indicators are defined as:

$$
\begin{array}{r}
V_{c k}^{C}=\frac{\sum_{s=1}^{p} V_{s k}}{p} \\
V_{c k}^{Q}=\frac{\sum_{g=1}^{q} V_{g k}}{q}
\end{array}
$$

for cost and quantity respectively, where " $p$ " is the total number of sub-chapters and " $\mathrm{q}$ " is the total number of complex groups that are part of chapter "c", during period " $k$ ". The project deviations, during period " $k$ ", are calculated as:

$$
V_{P k}^{C}=\frac{\sum_{c=1}^{r} V_{c k}^{C} \sum_{s=1}^{p} C_{s k}^{p}}{\sum_{c=1}^{r} \sum_{s=1}^{p} C_{s k}^{p}}
$$




$$
V_{P k}^{Q}=\frac{\sum_{c=1}^{r} V_{c k}^{Q} \sum_{g=1}^{q} Q_{g k}^{p} D_{g}}{\sum_{c=1}^{r} \sum_{g=1}^{q} Q_{g k}^{p} D_{g}}
$$

where " $r$ " is the total number of chapters that make up the project.

\subsection{Evaluation and Report}

The results need to be reliable, facilitate a rapid knowledge of the situation, and allow an in-depth analysis of the causes. To this end, two analyses are carried out when the survey is compared against the reference image. First a simple report is made and then a control chart is generated.

The control charts are the representation of the indicators of each chapter for each time period, equations (10) and (11), divided by the corresponding standard deviation for the same period. The standard deviation is determined for the population made up by the individual indicators of the sub-chapters. There is a standard deviation determined per time period. First, the mean of the indicators of the complex quantities and sub-chapter costs are calculated, respectively,

$$
\bar{V}_{k}^{C}=\frac{\sum_{s=1}^{r} V_{s k}}{r} ; \bar{V}_{k}^{Q}=\frac{\sum_{g=1}^{r} V_{g k}}{r}
$$

where " $r$ " is the total number of sub-chapters or total of complex quantities during period "k".

The standard deviation during the period " $\mathrm{k}$ " is then calculated,

$$
S_{k}^{Q}=\sqrt{\frac{\sum_{g=1}^{r}\left(V_{s k}-\bar{V}_{k}^{Q}\right)^{2}}{r-1}} ; S_{k}^{C}=\sqrt{\frac{\sum_{s=1}^{r}\left(V_{s k}-\bar{V}_{k}^{C}\right)^{2}}{r-1}}
$$

The control chart centre is set at 0 , which indicates that there is no difference between planned and actual values. The upper and lower control limits are established at $\pm 1.5 \mathrm{~S}_{k}^{C}, \pm 1.5 \mathrm{~S}_{k}^{Q}$, for cost and quantity control, respectively. The zone inside these control limits represents approximately $86 \%$ of the population in a normal distribution. In SPC, three periods that show an increasing trend towards the upper limit or a decreasing trend towards the lower limit, even though they may remain within the control limits, indicate that the processes need to be corrected [8].

\section{CASE STUDY}

The previously explained model is used to control the construction of $6,553 \mathrm{~m}^{2}$ for 48 dwellings in social housing in Cadiz, Spain. The buildings are of six storeys each, with an underground parking area, and a ground level plus another 4 storeys. Each dwelling has a lounge, kitchen, hallway, 3 bedrooms, and one bathroom. The building foundation is a reinforced concrete pad and has reinforced concrete walls for the underground parking area. The rest of the structure consists of concrete footings and one-directional beams. The façade is made of a double brick wall with an insulated cavity, coated with waterproof mortar on the outside, plaster on the inside, and both sides are painted. The finishes are typical for social housing: terrazzo floor, aluminium-framed windows, and wooden interior doors. The roof is flat and transmittable, except for the stairway case which has a sloped roof with Arabic tiles. For the project duration, there is no material nor manpower scarcity. The construction location has no accessibility problems.

In Tables $\mathbf{2}$ and $\mathbf{3}$, the total amount of each sub-chapter is distributed throughout the various time periods. The "code" column refers to the sub-chapter code and the "description" is its corresponding short definition as defined in ASICS. Since the work schedule can be revised several times during the project development, the work already completed during old schedules is entered in the third column, named "base", and the remaining work to be distributed in the new schedule is entered in column 4, named "work". In this way the manager is kept up to date with the amount of remaining work. The column denoted "total" is the sum of all weights in the sub-chapter,

$$
\operatorname{Total}_{s}=\sum_{k=1}^{n} W_{s k}
$$

Finally, columns " $\mathrm{T}_{1}, \mathrm{~T}_{2}, \ldots, \mathrm{T}_{\mathrm{n}}$ " represent the weights corresponding to the work distributed in " $\mathrm{n}$ " time periods.

Tables 2 and $\mathbf{3}$ represent the schedule in terms of cost of the first four months of the project. The sub-chapter costs include manpower, materials, and machinery costs. However, the model allows the control level to be focused on any specific aspect, for example, to control only material cost. This is possible since ASICS defines each type of cost, (manpower, material, and machinery), separately within a unitary price. The decision depends on the critical aspect which needs to be controlled more closely.

In Tables $\mathbf{2}$ and $\mathbf{3}$, the work distribution of chapters 02 and 03 (except for sub-chapter $03 \mathrm{H}$ ) takes place almost completely within the first 4 months, in time periods $T_{1}$ to $T_{4}$ in the project, and hence the four periods add up to 100 as shown in column "Total". Work of other sub-chapters is not $100 \%$ completed during those four periods and only a partial planning is represented, which adds up to less than 100. In the case study, $\mathrm{W}_{\mathrm{sk}}$ represents the percentage of work which takes place during period " $k$ ". However, other weighting values can be used, such as concrete cubic metres consumed in the foundation during each period; in fact, during each period, any characteristic that describes the work intensity during the project execution can be used. Finally, the total amount of the characteristic is added up in the "Total" column, and the percentage corresponding to each period is determined and is used to define the reference values or images in terms of Euros. Similar tables are generated for the schedule in terms of complex quantity classification in Tables $\mathbf{4}$ and 5. The main difference between the two tables is the demolition chapter, which does not exist as a "complex quantity" owing to the difficulties in developing new combinations from the cost classification system.

In Tables $\mathbf{4}$ and $\mathbf{5}$, the first and second columns, "code" and "description", are the code from ASICS and a short description, respectively. The "description" contains the measurement unit of the quantities. Additionally, the new 
Table 2. The work schedule in terms of cost for the first three chapters and first four months (I).

\begin{tabular}{|c|c|c|c|c|c|c|c|c|}
\hline $01 \mathrm{~A}$ & Bricks & & & 0 & & & & \\
\hline $01 \mathrm{E}$ & Enclosures & & & 0 & & & & \\
\hline $01 \mathrm{~L}$ & Installations & & & 0 & & & & \\
\hline 01Q & Roof & & & 0 & & & & \\
\hline $01 \mathrm{R}$ & Finishes & & & 0 & & & & \\
\hline $01 \mathrm{~S}$ & Water disposal & & & 0 & & & & \\
\hline 01 & DEMOLITION & & 631.06 & & & & & \\
\hline $02 \mathrm{~A}$ & Open excavations & & 2027.03 & 100 & 100 & & & \\
\hline $02 \mathrm{P}$ & Pads & & 39547.92 & 100 & 57 & 25 & 18 & \\
\hline $02 \mathrm{R}$ & Refilled and compacting & & 454.24 & 100 & 57 & 25 & 18 & \\
\hline $02 \mathrm{~T}$ & Transport & & 74127.52 & 100 & 57 & 25 & 18 & \\
\hline $02 \mathrm{~W}$ & Others & & & 100 & 57 & 25 & 18 & \\
\hline $02 Z$ & Trenches & & 105.20 & 100 & 57 & 25 & 18 & \\
\hline $03 \mathrm{~W}$ & Others & & & 0 & & & & \\
\hline 03 & FOUNDATIONS & & 74127.52 & & & & & \\
\hline $04 \mathrm{C}$ & Hanging pipelines & & 3319.37 & 100 & & & & \\
\hline $04 \mathrm{E}$ & Underground pipelines & & 9995.13 & 100 & & & & \\
\hline $04 \mathrm{~V}$ & Vertical pipelines & & 854.54 & 100 & & & & \\
\hline $04 \mathrm{~W}$ & Others & & 2126.23 & 100 & & & & \\
\hline 04 & WATER DISPOSAL & & 16295.26 & & & & & \\
\hline $05 \mathrm{~A}$ & Steel & & & 0 & & & & \\
\hline $05 \mathrm{~F}$ & Concrete slab & & 234691.39 & 100 & & & & \\
\hline $05 \mathrm{H}$ & Reinforced concrete & & 388.34 & 100 & & & & \\
\hline $05 \mathrm{M}$ & Wood & & & 0 & & & & \\
\hline $05 \mathrm{~W}$ & Others & & 6520.47 & 100 & & & & \\
\hline 05 & STRUCTURES & & 241600.20 & & & & & \\
\hline $06 \mathrm{~A}$ & Arches and vaults & & & 0 & & & & \\
\hline
\end{tabular}


(Table 2) contd....

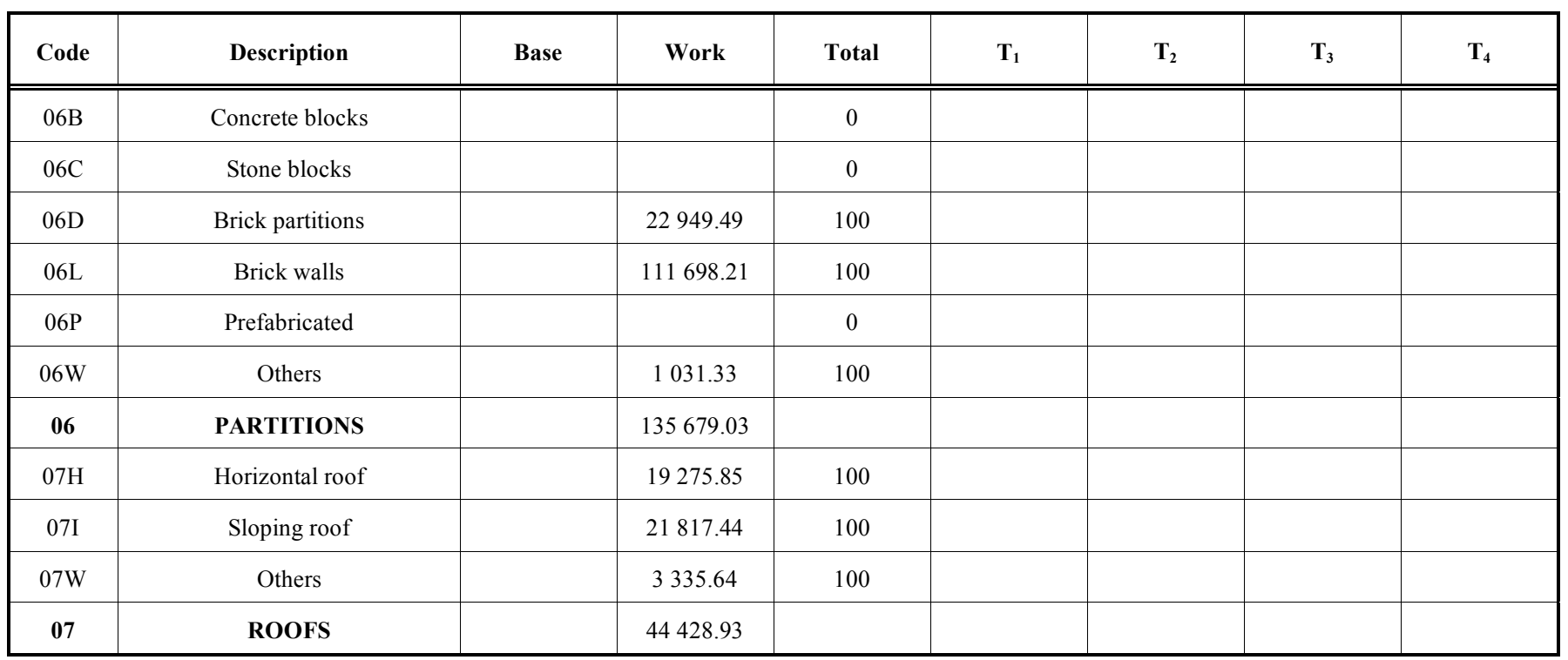

Table 3. The work schedule in terms of cost for the first three chapters and first four months (II).

\begin{tabular}{|c|c|c|c|c|c|c|c|c|}
\hline $08 \mathrm{C}$ & Air conditioning & & & 0 & & & & \\
\hline $08 \mathrm{~F}$ & Water & & 1351.57 & 100 & & & & \\
\hline $08 \mathrm{~L}$ & Gas & & & 0 & & & & \\
\hline 08P & Fire protection & & 327.73 & 100 & & & & \\
\hline $08 \mathrm{~V}$ & Audiovisual & & 17388.15 & 100 & & & & \\
\hline $08 \mathrm{~S}$ & Hygiene & & & 0 & & & & \\
\hline 09I & Waterproofing & & 454.24 & 100 & & & & 8 \\
\hline 09T & Thermal & & & 0 & & & & \\
\hline $09 \mathrm{~W}$ & Others & & & 0 & & & & \\
\hline 09 & INSULATION & & 454.24 & & & & & \\
\hline $10 \mathrm{~A}$ & Cladding & & 26124.89 & 100 & & & & \\
\hline $10 \mathrm{C}$ & Continuous & & 49651.67 & 100 & & & & \\
\hline $10 \mathrm{~L}$ & Lightweight & & & 100 & & & & \\
\hline
\end{tabular}


(Table 3) contd....

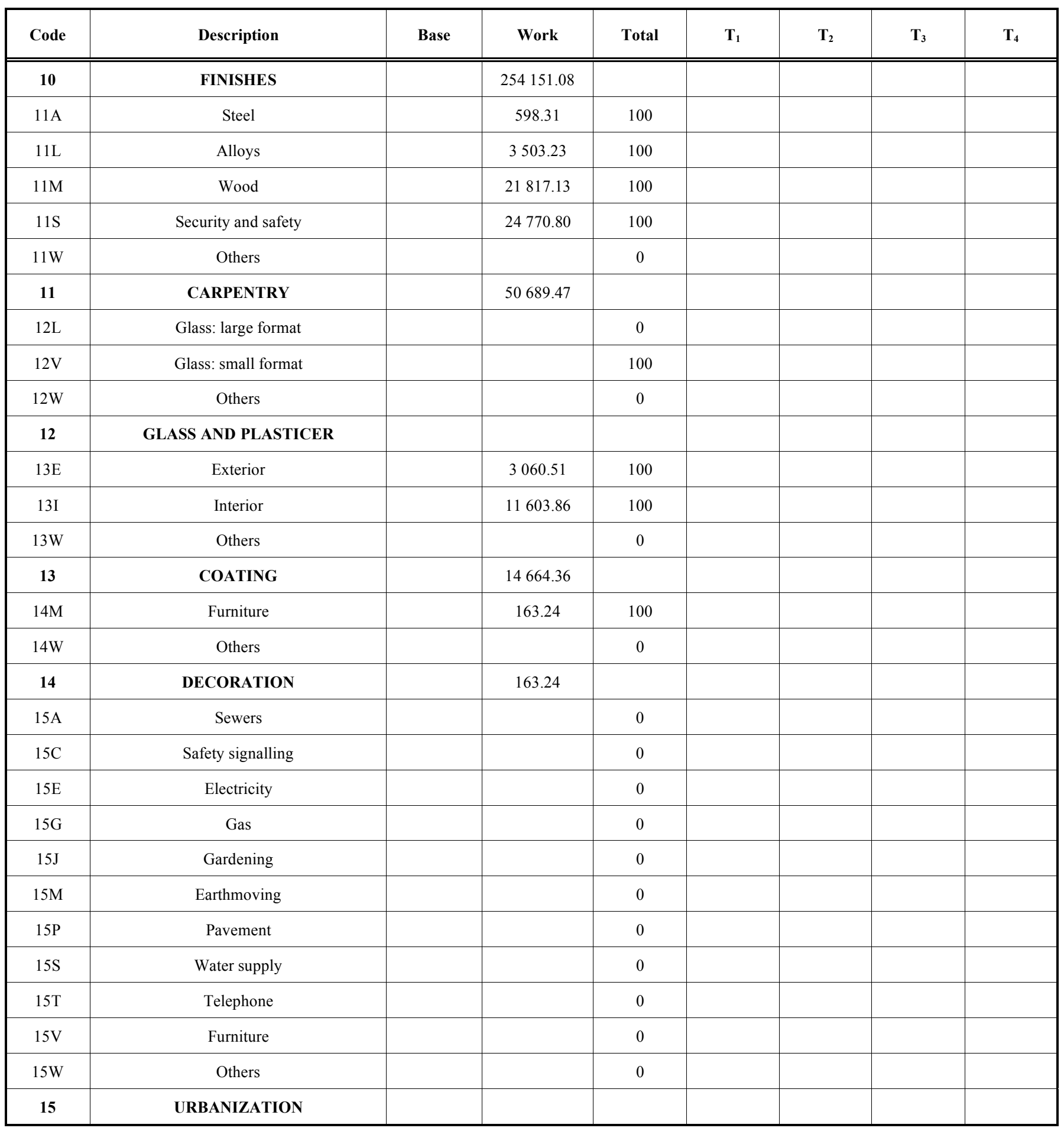

coefficient $\mathrm{D}_{\mathrm{g}}$ is defined for the current project in the column with the same name. In the project, each sub-chapter average price is divided by the most expensive item in the project: 03HAZ00030 trenches of reinforced concrete, their cost being $168.66 \mathrm{Euro} / \mathrm{m}^{3}$. For example, the 02EX group has an average cost of 5.06 Euro $/ \mathrm{m}^{3}$ and its corresponding $\mathrm{D}_{\mathrm{g}}$ is 0.03 .

Once the schedule is defined, the next step involves the collection and organization of the actual data at the construc- tion site. After the data is collected it is input into Tables 6 and 7, column " $\mathrm{C}_{\mathrm{R}}$ " being the real values paid up to that period. A comparison is then performed between the planned scenario $\left(C_{P}\right)$ and the actual scenario $\left(C_{R}\right)$. The $C_{P}$ column is determined by means of equations (6) and (7), for example the $03 \mathrm{H}$ group during period $\mathrm{T}_{4}$ is the result of the accumulation of previous periods,

$$
\begin{aligned}
\mathrm{C}_{\mathrm{P}} & =74127.52 *(0.0+0.0+0.35+0.20) \\
& =40770.00 \text { Euros }
\end{aligned}
$$


Table 4. The work schedule in terms of complex quantities for the first three chapters (I).

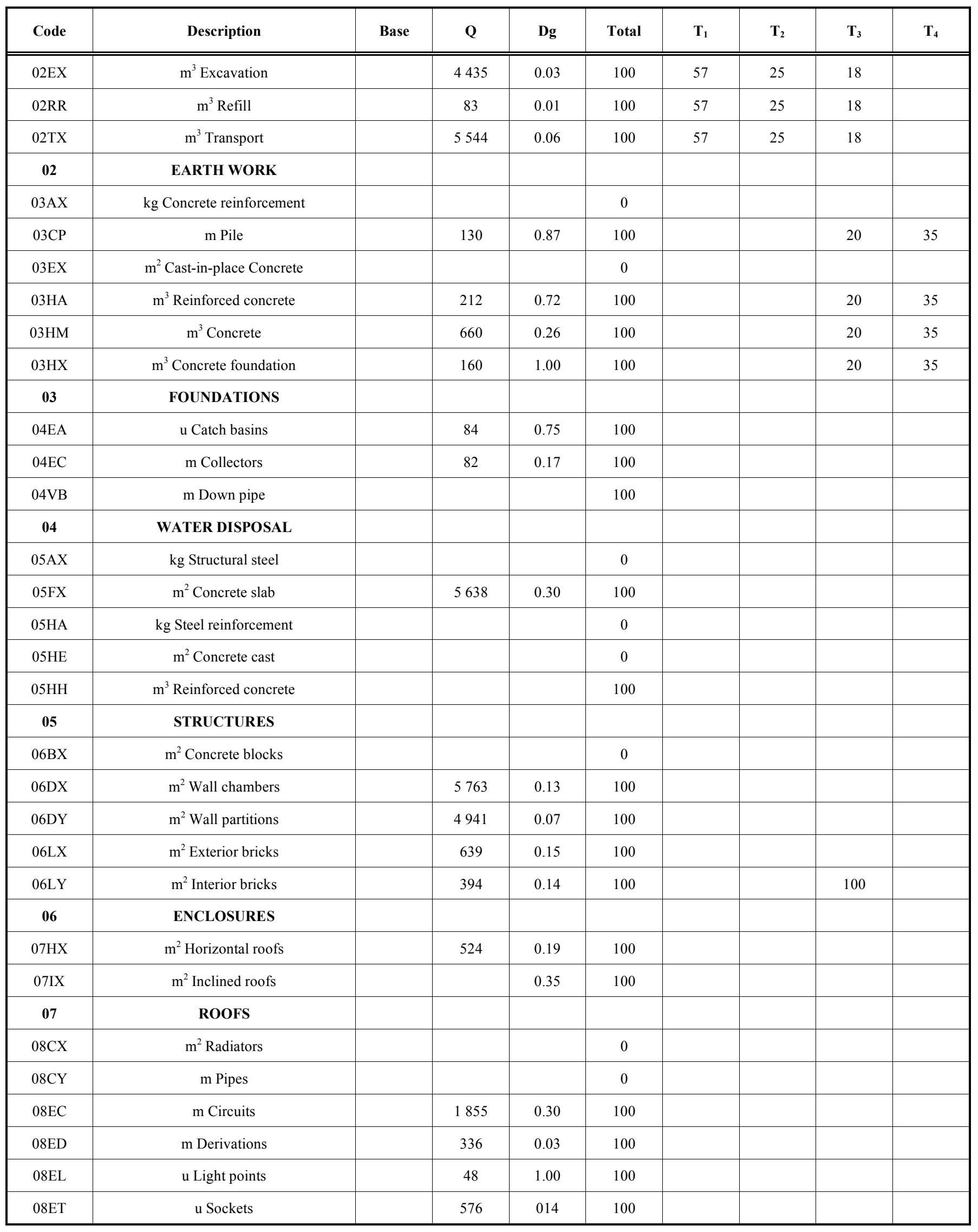


(Table 4) contd....

\begin{tabular}{|c|c|c|c|c|c|c|c|c|c|}
\hline 08EP & m Ground connection & & 2 & 0.55 & 100 & & & & \\
\hline 08FD & u Drains & & 48 & 0.12 & 100 & & & & \\
\hline 08FS & u Bathroom appliances & & 48 & 0.43 & 100 & & & & \\
\hline 08FT & u Thermos / heaters & & & 0.78 & 100 & & & & \\
\hline 08 & INSTALLATIONS & & & & & & & & \\
\hline
\end{tabular}

Table 5. The work schedule in terms of complex quantities for the first three chapters (II).

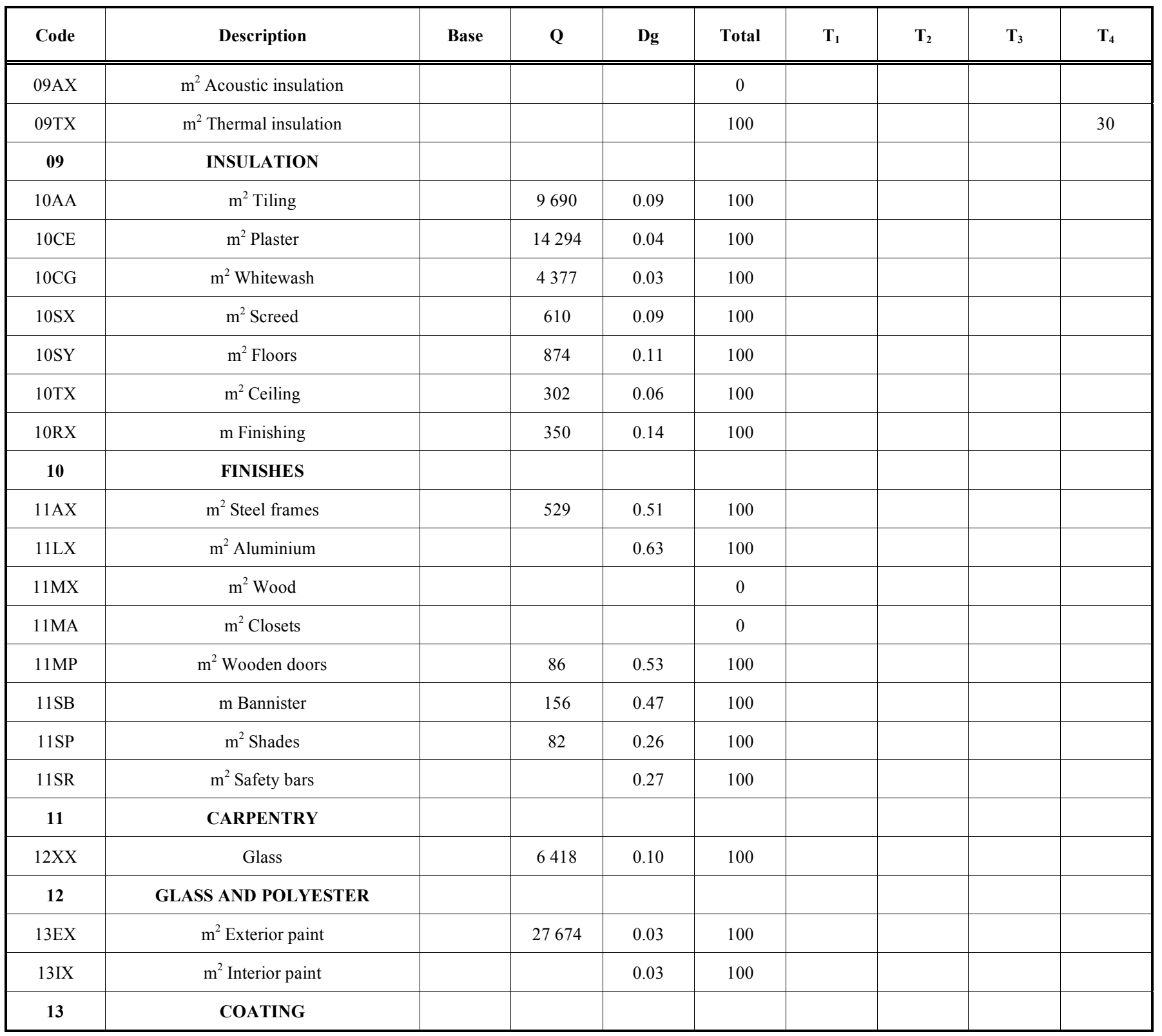


Table 6. Cost comparison table, during Period $\mathrm{T}_{4}$ (I).

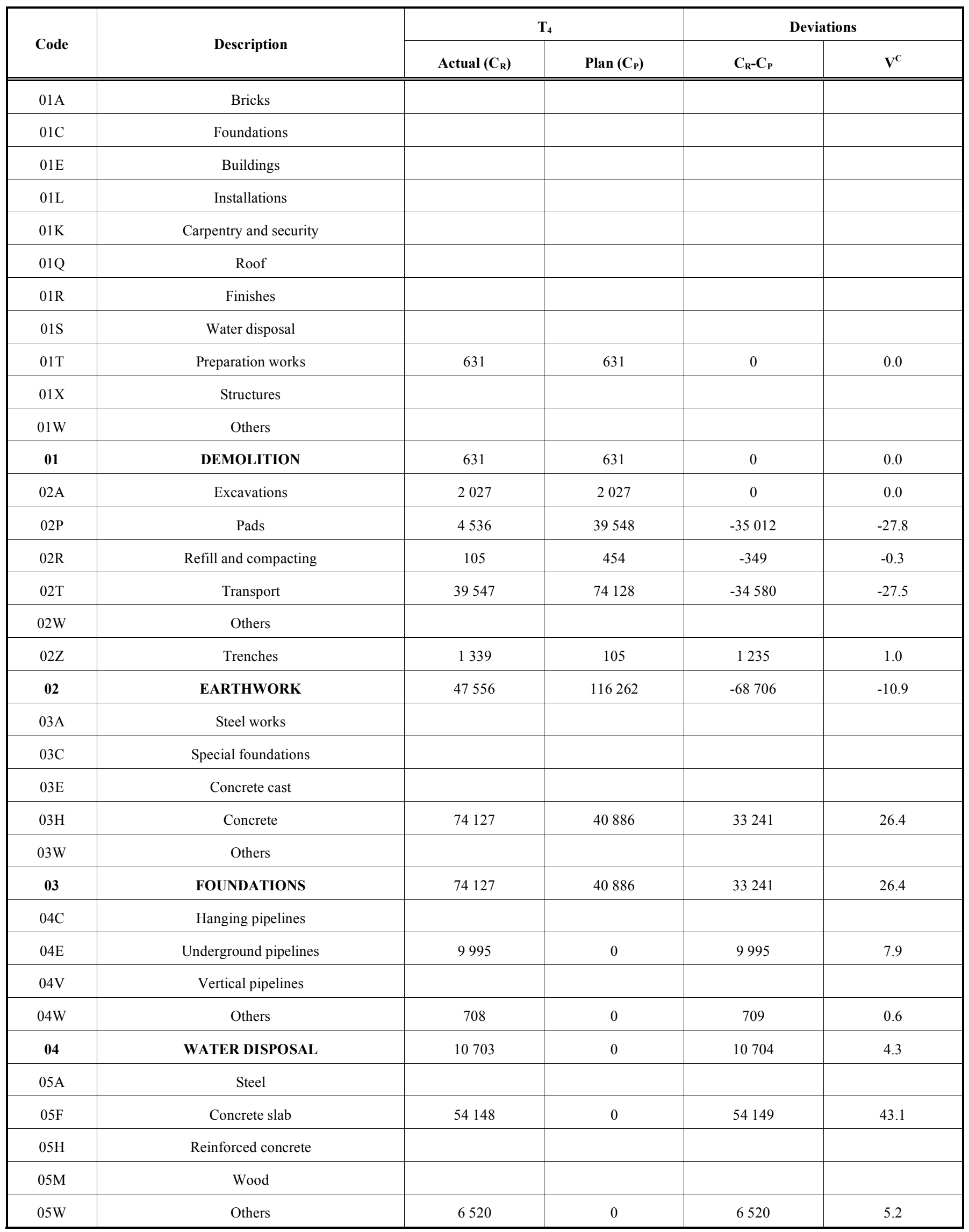


(Table 6) contd....

\begin{tabular}{|c|c|c|c|c|c|}
\hline Code & Description & Actual $\left(C_{R}\right)$ & Plan $\left(C_{P}\right)$ & $\mathbf{C}_{R^{-}}-\mathbf{C}_{\mathrm{P}}$ & $\mathbf{V}^{\mathrm{C}}$ \\
\hline $06 \mathrm{~A}$ & Arches and vaults & & & & \\
\hline 06B & Concrete blocks & & & & \\
\hline $06 \mathrm{D}$ & Brick partitions & & & & \\
\hline $06 \mathrm{~L}$ & Brick walls & & & & \\
\hline 06P & Prefabricated & & & & \\
\hline 07I & Sloping roof & & & & \\
\hline $07 \mathrm{~W}$ & Others & & & & \\
\hline 07 & ROOFS & & & & \\
\hline
\end{tabular}

Table 7. Cost comparison during Period $\mathrm{T}_{4}$ (II).

\begin{tabular}{|c|c|c|c|c|c|}
\hline Code & Description & \multicolumn{2}{|c|}{$\mathbf{T}_{4}$} & \multicolumn{2}{|c|}{ Deviations } \\
\hline $08 \mathrm{E}$ & Electricity & & & & \\
\hline $08 \mathrm{~F}$ & Water & & & & \\
\hline $08 \mathrm{M}$ & Electro-mechanic appliances & & & & \\
\hline $08 \mathrm{P}$ & Fire protection & & & & \\
\hline $08 \mathrm{~V}$ & Audio-visual & & & & \\
\hline $09 \mathrm{~A}$ & Acoustic & & & & \\
\hline 09I & Waterproofing & 454 & 36 & 418 & 0.3 \\
\hline 09T & Thermal & & & & \\
\hline 09W & Others & & & & \\
\hline 09 & INSULATION & 454 & 36 & 418 & 0.3 \\
\hline $10 \mathrm{~A}$ & Cladding & & & & \\
\hline $10 \mathrm{C}$ & Continuous & & & & \\
\hline
\end{tabular}


(Table 7) contd....

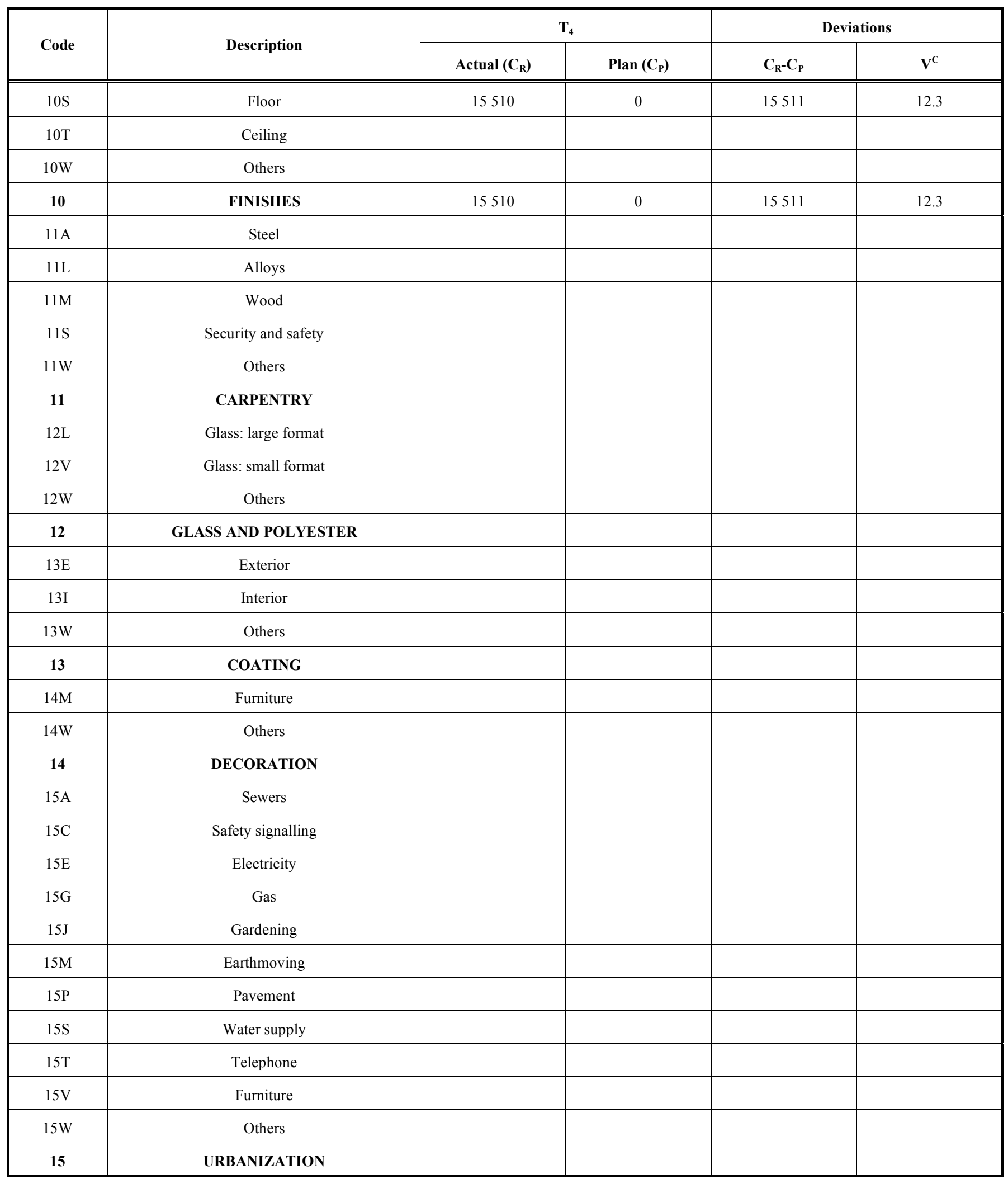

Tables 6 and 7 take place during period 4 (T4) which corresponds to the 4 th month since the project started. The indicators for each sub-chapter, column "V", are determined using equation (8). Equation (10) is applied to determine the indicator average value within a chapter, and finally, for the whole project, equation (12) is applied. Identical calculations are performed with the "complex quantities" using equations (9), (11) and (13). 
The next step, for the time period, is the completion of a simple report, as shown in Table 8. In the table, those indicators divided by the standard deviation which are equal to or bigger than \pm 1.5 are bold-faced, thereby highlighting processes outside the control limits.

The report can be easily understood by the project manager, (normally in charge of several projects), who only needs to look at the indicators in the cost and quantities to obtain the required information. Comments on the indicators are made in the report table, and recommendations can then be defined. Possible comments or recommendations will be kept simple, such as: for positive values, the process is slightly ahead of schedule, strongly ahead of schedule; or for negative values, the concrete was not delivered on time, the earthwork is slower than expected.
Once the report is completed, the next step is to graphically represent the indicators and identify the processes that are off target and susceptible to correction. The statistical variables are determined for each specific period of time. Figs. $(2,3)$ represent the indicators of each chapter up to period $\mathrm{T}_{4}$, of cost and quantities, respectively. The indicators are calculated using equations (12) and (13) divided by the standard deviation of the sample during the corresponding period. An indicator, which is higher than 1.5 , signifies that the cost or quantity has exceeded that of $86 \%$ of the population during the period, and is therefore considered in need of corrective action.

In Fig. (2), where the indicators for the first 4 months are represented, all indicators higher than 1.5 need to be checked and controlled. For example, it can be seen that Chapter

Table 8. Report of the production carried out in terms of cost and quantity.

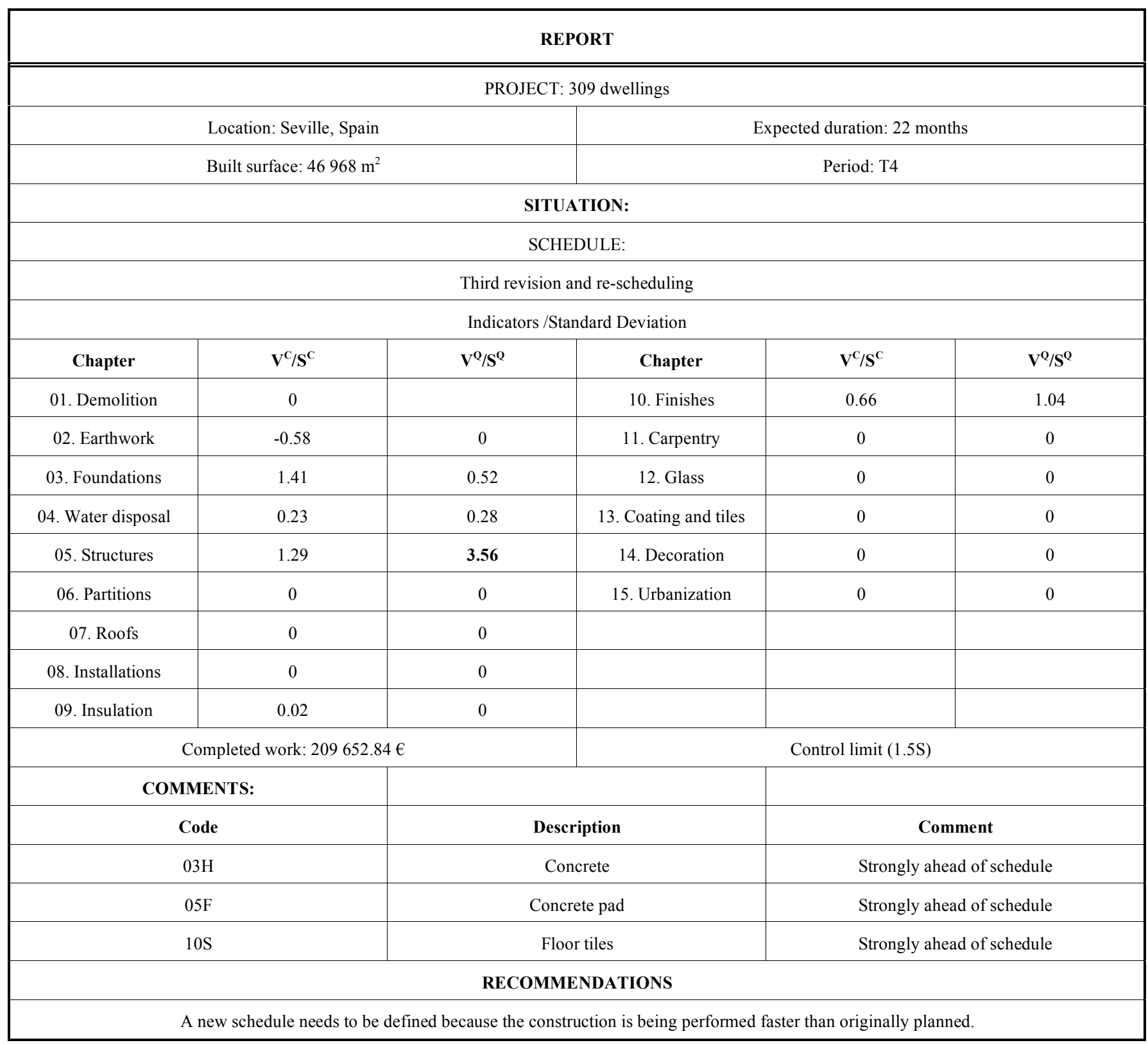


C03: Foundation has been significantly off schedule since month $2\left(\mathrm{~T}_{2}\right)$. The chapter needs to be checked and rescheduled. The same also happens with Chapter C04, Water disposal, during month $4\left(\mathrm{~T}_{4}\right)$.

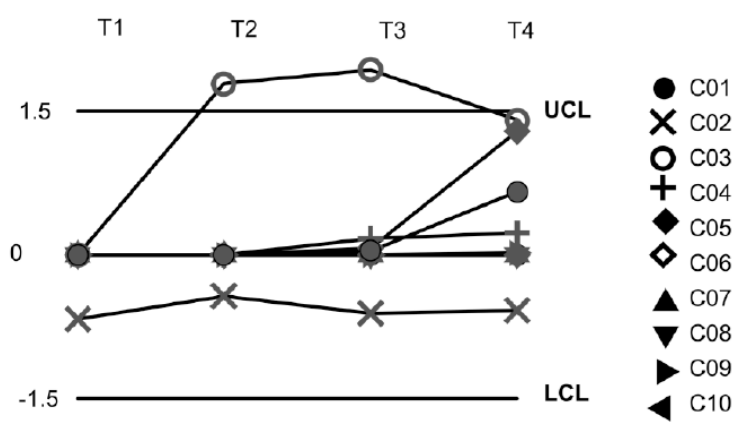

Fig. (2). Statistical process control of project cost.

On the other hand, the control chart for quantities (Fig. 3) shows slightly different behaviour since market cost fluctuations are not taken into consideration and only the quantities of work completed are considered. Moreover, the indicators are determined with respect to the total corrected quantities (by means of the $\mathrm{D}_{\mathrm{g}}$ correcting factor) in the project and not with respect to the total project cost. Chapter 03 Foundation is off target during month 2 because the work started earlier than planned, but this deviation is not significant in month 3 $\left(\mathrm{T}_{3}\right)$ and $4\left(\mathrm{~T}_{4}\right)$, since Chapter 06 is the important quantity in the project, even though it is not an important cost in (Fig. 2).

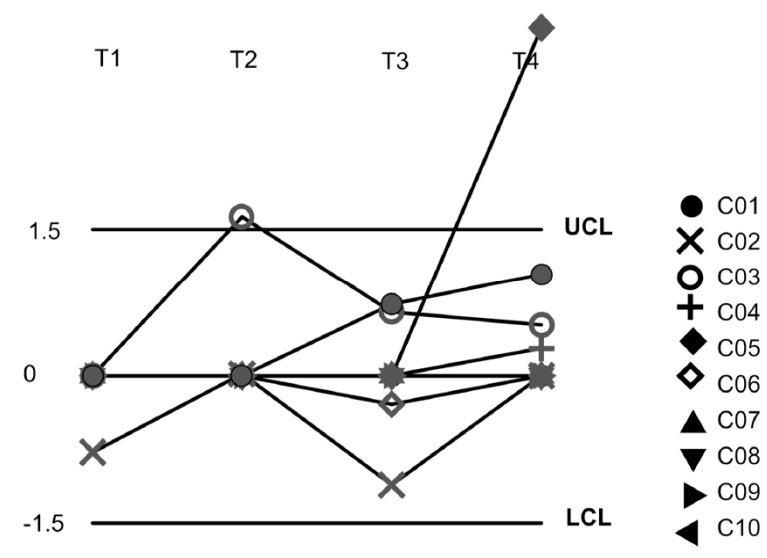

Fig. (3). Statistical process control of project quantities.

The tool improves the control of cost and schedule, especially at manager level, since a simple general graph indicates the overall construction site behaviour or that of several construction sites at the same time. The most important contribution of the control chart, as in any application of SPC, is that it provides a simple visual support to managers; this is especially significant under a multi-project management environment, since the representation remains in an identical form for all the projects. The same WBS is used, the indicators are dimensionless and independent of the project size, and the control limits can be set to identical values in all project graphs. The SPC general rules apply, as in industrial processes where SPC is commonly used: when three points are under the control limit but with increasing deviations or a major fluctuation takes place, then the process is considered out of control and this can be visually detected.

\section{CONCLUSION}

To guarantee the effectiveness of the model, the following objectives are met:

1. The model implementation is simple and quick; a commonly used spread sheet is the only software needed.

2. The information required in order to use the model is easy to obtain and causes no obstacles to the daily workload of the data collector.

3. The results are reliable since they are based on the cost data, which is a contractual commitment, and are represented by sensitive indicators that are easy to understand: mean and standard deviation.

4. The structure of the results facilitates rapid understanding of the general situation and also allows an in-depth analysis of the causes.

5. The cost of implementing the system is significantly lower than the savings provided by its use.

Future work involves the development of the classification system so that it includes the control of construction projects other than that of dwellings, such as libraries, gymnasiums, and school and college buildings. Furthermore, another alternative to this approach could involve the organization of the budget and activities through a process classification system instead of the present cost classification system.

\section{CONFLICT OF INTEREST}

The authors confirm that this article content has no conflict of interest.

\section{ACKNOWLEDGEMENTS}

Declared none.

\section{REFERENCES}

[1] L.J. Isidore and W.E. Back, "Probabilistic optimal cost schedule", J. Constr. Eng. Manage., vol. 127, pp. 431-437, June 2001.

[2] Z.I. Sakka and S.M. El-Sayegh, "Float consumption impact on cost and schedule in the construction industry", J. Constr. Eng. Manage., vol. 133, pp. 124-130, Feb. 2007.

[3] Y. Jung and S. Kang "Knowledge-based standard progress measurement for integrated cost and schedule performance control", $J$. Constr. Eng. Manage., vol. 133, pp. 10-21, Jan. 2007.

[4] Y.A. Olawale and M. Sun, "Cost and time control of construction projects: inhibiting factors and mitigating measures in practice", Constr. Manage Econ., vol. 28, pp. 509-526, 2010.

[5] H.L. Gantt, Organizing for Work. Howe: New York, 1919. Harcourt, Brace.

[6] J.J. Moder and C.R. Phillips, Project Management with CPM and PERT. Van Nostrand Reinhold: New York, 1970.

[7] M.A. Cox, "Simple normal approximation to the completion time distribution for a PERT network", Int. J. Proj. Manage., vol. 13, pp. 265-270, Apr. 1995.

[8] W.A. Shewhart, "Statistical method from the viewpoint of quality control". The Graduate School of the Department of Agriculture: Washington DC, 1939. 
[9] G.E.P. Box, A. Luceño, M.C. Paniagua-Quiñones, Statistical control by monitoring and adjustment. Hoboken, NJ: $2^{\text {nd }}$ ed. Wiley Series in Probability and Statistics. John Wiley \& Sons, Inc., 2009.

[10] J.F. MacGregor and T. Kourti, "Statistical process control of multivariate processes", Control Eng. Pract., vol. 3, pp. 403-414, Mar. 1995.

[11] R.L. Mason and J.C. Young, Multivariate statistical process control with industrial applications. SIAM: Philadelphia, 2002.

[12] S. Bersimis, S. Psarakis and J. Panaretos, "Multivariate Statistical Process Control Charts: an Overview", J. Qual. Reliab. Eng. Int., vol. 23, pp. 517-543, May 2007.

[13] G.M. Smith, Statistical process control and quality improvement. Pearson-Prentice Hall, Upper Saddle River, New Jersey, 2004.

[14] K.M. Nassar, W. M. Nassar and M.Y. Hegab, "Evaluating cost overruns of asphalt paving project using statistical process control methods", J. Constr. Eng. Manage., vol. 131, pp. 1173-1178, Nov. 2005.

[15] S.S. Leu, and Y.C. Lin, "Project performance evaluation based on statistical process control techniques", J. Constr. Eng. Manage., vol. 134, pp. 813-819, Oct. 2008.

[16] Electronic Industries Alliance (EIA). Earned value management systems. Publication no. ANSI/EIA-748. EIA: Arlington, VA, 1998.

[17] L.S. Kang and B.C. Paulson, "Information management to integrate cost and schedule for civil engineering projects", J. Constr. Eng. Manage., ASCE, vol. 124, pp. 381-389, May 1998.

[18] N.N. Eldin, "Management of engineering/design phase." J. Constr. Eng. Manage., vol. 117, pp. 163-175, Jan. 1991.

[19] Construction Specifications Institute, Masterformat manual of practice (MP2-1). Construction Specifications Canada (CSI/CSC): Alexandria, VA, 1983.

[20] Construction Specifications Institute, UniFormatTM: A Uniform classification of construction systems and assemblies. Construction Specifications Institute: Alexandria, VA, 1998.

[21] CESMS. Civil engineering standard method of measurement. London: $3^{\text {rd }}$ ed., Thomas Telford, 1991.
[22] A.R. Jones, CI/SfB construction indexing manual. Royal Institute of British Architects (RIBA) Publications Ltd.: London, UK, 1987.

[23] Uniclass-unified classification for the construction industry. National Building Specification Service Ltd.: London, UK, 1996.

[24] International Organization for Standardization (ISO) TC 59 $\mathrm{SC} / \mathrm{WG} 2$, Classification of information in the construction industry. ISO Tech. Report 14177, Oslo Norway, 1994.

[25] Consejería de Vivienda y Ordenación del Territorio de la Junta de Andalucía. Base de Costes de la Construcción de Andalucía 2013 (Andalusian Construction Costs Database 2013, Seville, Spain). $<\mathrm{http}$ ://www.juntadeandalucia.es/viviendayordenaciondelterritorio/ www/jsp/estatica.jsp?pma $=0 \&$ pmsa $=0 \& \mathrm{e}=$ planificacion/publicacio nes/banco_precios_construccion/bcca08rev2b/bcca08rev2b.html > [Accessed Jan 10, 2014].

[26] M. Marrero and A. Ramirez-de-Arellano, "The building cost system in Andalusia: application to construction and demolition waste management”, Constr. Manage. Econ., vol. 28, pp. 495-507, 2010.

[27] H.S. Lee and K.J. Yi, "Application of mathematical matrix to integrate project schedule and cost", J. Constr. Eng. Manage., vol. 125, pp. 151-742, May 1999.

[28] J. Solis-Guzman, M. Marrero, M.V. Montes-Delgado and A. Ramirez-de-Arellano, "A Spanish model for quantification and management of construction waste", Waste Manage., vol. 29, pp. 25422548, 2009.

[29] M. Marrero, J. Solis-Guzman, B. Molero-Alonso, M. OsunaRodriguez and A. Ramirez-de-Arellano, Demolition waste management in Spanish legislation. Open Construct. Build Tech. J., vol. 5 (Supl 2-M7), pp. 162-173, December 2011 [Online] Available; http://www.benthamscience.com/open/tobctj/articles/V005/ SI0123TOBCTJ/162TOBCTJ.pdf [Accessed Jan 21, 2013].

[30] Spanish Government - 2007 General Courts, Ley 30/2007, de 30 de octubre, de Contratos del Sector Público. (Law 30/2007, October 30, Contracts of the Public Sector). Edited by Official Bulletin, Spanish Government, Madrid, Spain.

Received: January 30, 2014

Revised: May 06, 2014

Accepted: May 08, 2014

(C) Marrero et al.; Licensee Bentham Open.

This is an open access article licensed under the terms of the Creative Commons Attribution Non-Commercial License (http://creativecommons.org/licenses/by-nc/3.0/) which permits unrestricted, non-commercial use, distribution and reproduction in any medium, provided the work is properly cited. 